\title{
Valoração econômica do trecho do Rio Tocantins referente à Orla Sebastião Miranda, Marabá/PA
}

O gerenciamento e uso inadequado dos recursos hídricos geram externalidades negativas à população, e a fim de internalizar a problemática se utiliza a valoração econômica dos cursos d'água. Este trabalho objetivou determinar o valor econômico do trecho do Rio Tocantins referente à Orla Sebastião Miranda, em Marabá - PA. O método utilizado foi o dedutivo, com abrangência quantiqualitativa, em associação ao levantamento bibliográfico no período entre 2012 e 2018 . Os dados primários foram coletados pela aplicação de 169 formulários em entrevistas informais, a partir do método de valoração contingente, com o uso da disposição a pagar e, das abordagens open-ended simples e referendum simples, para a pesquisa piloto ( 40 formulários) e final (129 formulários), respectivamente. A análise dos dados obtidos indicou, na pesquisa piloto, grande concordância entre os 40 entrevistados $(n=28 ; 70 \%)$ em pagar um valor anual para melhorias na conservação do rio, com uma taxa média de $\mathrm{R} \$ 22,75$ reais/ano. Na pesquisa final, a análise dos dados obtidos quanto à disposição a pagar, indicou que, maioria dos ambulantes $(\mathrm{n}=45 ; 77,6 \%)$ pagariam por essa manutenção; o outro grupo, dos estabelecimentos comerciais e prestadores de serviço apresentaram similaridade $(\mathrm{n}=23$ $60,5 \%$ ); bem como os ribeirinhos $(n=28 ; 84,8 \%$ ). O valor da DAPT calculada foi de $R \$ 3.467,907 /$ ano, para a população total, e $R \$ 178.902,326 /$ ano, quando se considerou o núcleo da Marabá Pioneira. Então, a comunidade está disposta a participar na conservação do corpo hídrico e, esses dados podem ser úteis no desenvolvimento de políticas públicas para a área.

Palavras-chave: Conservação; Indenização; Custo-benefício.

\section{Economic valuation of the Rio Tocantins stretch regarding the Sebastião Miranda Slide, Marabá/PA}

\begin{abstract}
The inappropriate management and use of the water resources generate negative externalities to population and, in order to internalize the problem, the watercourses economic valuation is used. This work aimed to determine the economic value of the Tocantins River stretch along Sebastião Miranda waterfront, in Marabá - PA. The used method was the deductive, with quantitative and qualitative scope, associated with bibliographic survey between 2012 and 2018 . The primary data were collected through the application of 169 forms during informal interviews, from the contingent valuation method, with the use of the willingness to pay, and the simple open-ended approaches and referendum, for the pilot research ( 40 forms) and final research ( 129 forms), respectively. The obtained data analyze indicated, in the pilot research, a huge agreement among the 40 interviewed $(n=28 ; 70 \%)$ in paying an annual value for improvements in the river conservation, with a mean tax of R\$22, 75 per year. In the final research, the data analyze from the willingness to pay indicated that, most of the street vendors $(n=45 ; 77,6 \%)$ would pay for this maintenance; the other group, of the commercial establishments and service providers, have shown similarities ( $n=23 ; 60,5 \%$ ), just as the riverside population $(n=28 ; 84,8 \%$ ). The total willingness to pay (DAPT) value calculated was $R \$ 3.467,907$ per year for the total population, and R\$ $178.902,326$ per year, when Marabá Pioneira district was considered. Thereby, the community is willing to participate in the watercourse conservation and these data can be useful in public policies development for the area.
\end{abstract}

Keywords: Conservation; Indemnity; Cost-benefit.

Topic: Valoração e Economia Ambiental

Reviewed anonymously in the process of blind peer.
Received: 05/03/2021

Approved: 28/03/2021
Emanoelen Bitencourt e Bitencourt (iD) Universidade do Estado do Pará, Brasil http://lattes.cnpq.br/4706004419015995 http://orcid.org/0000-0002-5560-6347 manuhbitencourt13@gmail.com

\section{Antônio Pereira Júnior (iD}

Universidade do Estado do Pará, Brasil http://lattes.cnpq.br/3239362677711162 http://orcid.org/0000-0001-6241-985X antonio.junior@uepa.br
Referencing this:

BITENCOURT, E. B.; PEREIRA JUNIOR, A.. Valoração econômica do trecho do Rio Tocantins referente à Orla Sebastião Miranda, Marabá/PA. Revista Ibero Americana de Ciências Ambientais, v.12, n.3, p.748-763, 2021. DOI: http://doi.org/10.6008/CBPC2179$\underline{6858.2021 .003 .0059}$ 


\section{INTRODUÇÃO}

Os acontecimentos que envolvem problemas ambientais estão relacionados não somente a desequilíbrios ecológicos provocados pelo desmatamento e poluição dos rios, por exemplo. Mas, eles atrelam-se a questões econômicas, políticas e sociais, que direta ou indiretamente, afetam o bem-estar e qualidade de vida do homem e demais seres vivos presentes nos meios biofísico e socioambiental (AREGAY et al., 2016).

Todavia, notaram-se estes desequilíbrios, com maior expressão, apenas a partir de momentos em que os seres humanos foram expostos a riscos ambientais, como a radioatividade, o incremento na concentração de dióxido de carbono $(\mathrm{CO} 2)$ no ar atmosférico e a perda da potabilidade da água. As consequências dessa exposição foram e ainda são catastróficas, como doenças e mortes na população (RADOVIC, 2016).

Uma das razões dessa problemática é o parco conhecimento da sociedade acerca das interações ecossistêmicas, ou seja, entre o meio físico e biótico. Esse desconhecimento ocasiona uso incorreto de recursos hídricos. Além disso, há um mau gerenciamento ambiental, tanto público quanto privado, nos quais falta sistematização adequada, políticas abrangentes e fiscalização eficiente no que tange ao impacto biossistêmico. Em função disso, as externalidades negativas (Ex.: resíduos sólidos e poluição hídrica) ficam para a população (LEANDRO et al., 2015).

Nesse sentido, é preciso internalizar essas externalidades. Mas, os serviços ambientais não têm valor de mercado, portanto, estes não se adequam a uma investigação fundamentada na teoria econômica clássica, e isso permitiu o surgimento da economia do meio ambiente, na segunda metade do século XX. Ela é voltada à valoração econômica dos recursos naturais, sendo um aporte a novas percepções de gerenciamento/desenvolvimento e tomada de decisões para elaboração de ações, sejam elas pública e/ou privada (SOUSA et al., 2013).

Quanto à valoração de bens e serviços ambientais, sabe-se que ela possibilita uma avaliação socioeconômica dos impactos gerados pelas atividades econômicas, como transporte, comércio e extrativismo. Isto porque todo parecer a respeito do uso dos recursos naturais abrange a determinação de valor monetário, com a finalidade de melhor aplicar as formas de mediação na relação custo/benefício (PEREIRA JÚNIOR, 2014).

Acerca do valor econômico de um recurso ambiental (VERA), este existe conforme é empregado e provoca modificações nos níveis de produção e consumo (dificuldade do uso de um recurso hídrico devido à poluição), ou seja, no bem-estar da população, porque há alteração na disponibilidade deste. Com isso, o VERA pode ser mensurado a partir de interesses particulares de uso ou conservação dos bens e serviços (JACOSKI et al., 2015).

Em suma, os impactos socioambientais negativos, gerados no desenvolvimento de atividades antrópicas, representam um problema que necessita de estudos e exploração para a internalização destes, especialmente em áreas onde há vasta utilização dos recursos ambientais. Por isso tudo, o objetivo da 
pesquisa foi determinar o valor econômico do trecho do rio Tocantins, onde foi implantada a Orla Sebastião Miranda, em Marabá (PA), e relacioná-lo aos dados de percepção ambiental da população que exerce atividades de influência na área.

\section{REVISÃO TEÓRICA}

\section{Valoração de bens e serviços ambientais}

Os recursos naturais como, por exemplo, os peixes, e atributos ambientais (Ex.: qualidade da água), são ativos ambientais de muito valor, visto que geram um fluxo de bens e serviços ecossistêmicos, que são em número de quatro: (1) de provisão, produtos conseguidos - comida e água; (2) de regulação, benefícios advindos de processos naturais - regulação climática; (3) culturais, proveitos imateriais - espirituais, recreação e apreciação da paisagem; e (4) de suporte, indispensáveis para a existência dos demais - produção de oxigênio e formação de solos (CARVALHO, 2015).

Ainda que alguns destes bens e serviços possuam valor econômico, como água e solo, outros (Ex.: regulação climática) não são incluídos no sistema de preços do comércio (SILVA et al., 2017). Logo, a quantia monetária atribuída é inadequada, e o custo ou benefício deles não representa o valor social dos mesmos, ou seja, não contempla a real grandeza da produção ou consumo, e isso gera a sociedade externalidades negativas que revelam as deficiências nos preços de mercado, quando o sistema não reflete os resultados de determinada atividade (LIMA et al., 2016; SOUZA, 2016).

Portanto, a valoração é relevante para mitigar ou compensar impactos ambientais, visto que o valor obtido expõe o grau da degradação ocasionada, e é tomado como referência, então pode auxiliar em indenizações determinadas pelos órgãos jurídicos ambientais. Além disso, é um indicador na avaliação de custos e benefícios, auxilia em optações por prioridades de investimentos/tomada de decisão e abrange a proteção ética do meio ambiente, assim como aspectos culturais, religiosos e estéticos (LIMA, 2018).

\section{Valoração Econômica De Recursos Ambientais (VERA)}

Dentre os inúmeros problemas relacionados à VERA, encontram-se os direitos de propriedade dos recursos mal definidos e características de bens públicos, como a água, os quais são não-excludentes e nãorivais, ou seja, não se pode negar o uso do bem a quaisquer indivíduos e ele pode ser utilizado de forma concomitante por várias pessoas, respectivamente, por isso a vontade de pagar por eles tende a ser baixa (SANTOS et al., 2017; SOUSA et al., 2016).

O valor de um recurso ambiental como a água, por exemplo, não pode restringir o acesso deste, para não infringir o direito de uso de todos. Sendo, portanto, imprescindível equilibrar o valor, tanto no intuito de evitar danos e perda dos serviços ambientais, como o desperdício, quanto para atender os princípios constitucionais (PACHECO, 2015).

Esses problemas podem influenciar na determinação desse tipo de valor, a qual é feita por métodos diversos que ocorrem de forma estratégica, visto que as táticas utilizadas são modificadas de acordo com 
cada problema identificado. Logo, as grandezas econômicas são distintas e podem ser obtidas com a aplicação de mais de um método como: (1) produtividade marginal, (2) preços hedônicos, (3) custos de viagem, e (4) valoração contingente (PAIVA, 2015).

Quanto ao Método da Valoração Contingente (MVC), além de ser utilizado para questionar sobre optações das pessoas por bens públicos, é o único capaz de mensurar valores de existência, sendo reconhecido e validado por meio do relatório do Panel of the National Oceanic and Atmospheric Administration (NOAA), em 1993, para avaliar monetariamente a perda de bem-estar por modificações ambientais. Logo, este é confiável o bastante em sentenças judiciais e administrativas, para a indenização de danos aos recursos naturais (MUÑOZ, 2015; ROMO-LOZANO et al., 2017).

\section{METODOLOGIA}

A pesquisa foi desenvolvida com a aplicação do método dedutivo (MATIAS-PEREIRA, 2016), que parte de duas premissas verdadeiras e produz uma conclusão verdadeira: (1) os recursos ambientais podem ser valorados economicamente; (2) o rio é um recurso ambiental; então, o corpo hídrico pode ser valorado economicamente.

A pesquisa teve abrangência quantitativa porque os dados obtidos foram demonstrados em números, e qualitativa devido à abordagem descritiva dos aspectos relacionados ao meio ambiente e os recursos naturais (SEVERINO, 2017).

Os dados pretéritos foram obtidos em links especializados e em banco de dados de acesso livre: Scientific Eletronic Library Online (SciELO), Coordenação de Aperfeiçoamento do Pessoal de Nível Superior (CAPES), dentre outros. O recorte temporal situou-se entre 2012 e 2018, para que se buscassem literaturas mais atualizadas, exceto pelo uso de IBGE (1993).

\section{Fisiografia do município}

O estudo foi realizado no município de Marabá, localizado na mesorregião Sudeste Paraense, com

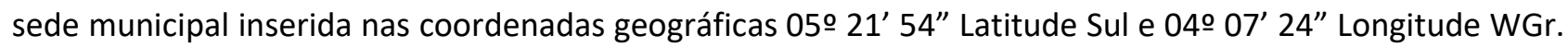
No município, prevalecem os solos Podzólico Vermelho-Amarelo e Latossolo Vermelho-Amarelo distrófico, e a Floresta Densa Submontana. Em relação à topografia, as cotas máximas são de cerca de $700 \mathrm{~m}$ na parcela próxima a Serra dos Carajás. Os principais rios são o Itacaiúnas e Tocantins. O clima, na classificação de Köppen, está em transição de AW para Am, com uma temperatura média anual de 26,50 C e índice pluviométrico de aproximadamente $2.000 \mathrm{~mm} / \mathrm{ano}$ (FAPESPA, 2016)

\section{Área de estudo}

A área de estudo é referente ao trecho do rio Tocantins correspondente à extensão da Orla Sebastião Miranda (quase $3 \mathrm{~km}$ ), fundada na margem esquerda do rio, localizada na Avenida Marechal Deodoro, Núcleo da Marabá Pioneira, Marabá - PA, mas para esta pesquisa foram consideradas ambas as margens do corpo 
hídrico (Figura 1).

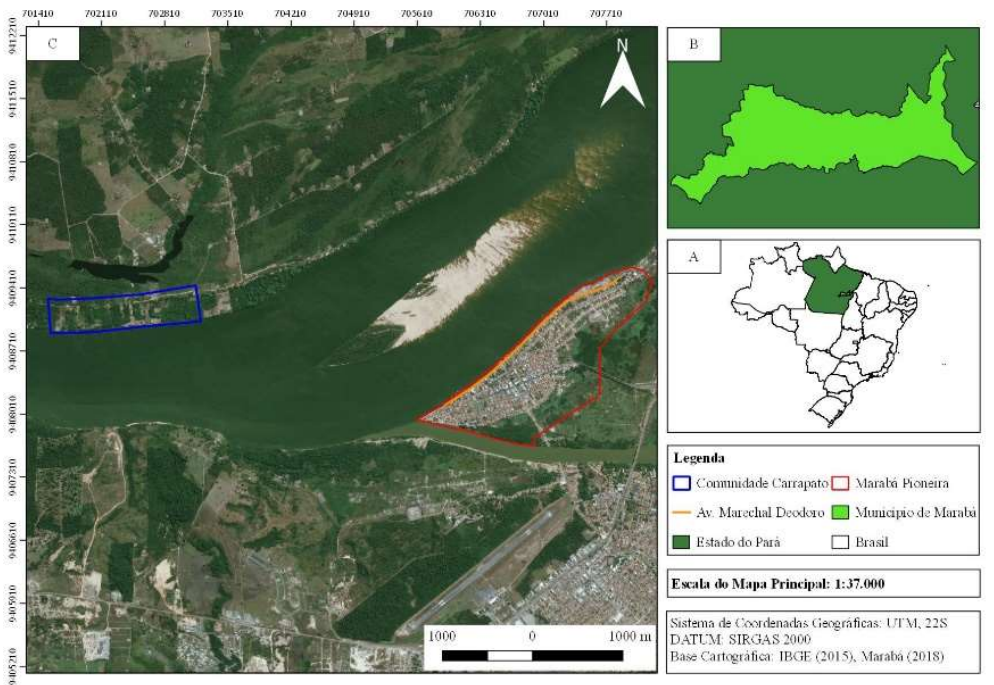

Figura 1: a) Mapa de localização do Pará; e b) do município de Marabá; c) Vista superior da área objeto dessa pesquisa: trecho do rio Tocantins referente à Orla Marítima de Marabá - PA.

\section{Coleta de dados}

A coleta de dados primários foi efetuada conforme as orientações de Oliveira (2015) e a síntese escrita pelo Painel NOAA (COSTA et al., 2015). Foram aplicados 169 formulários em entrevistas informais pessoais, pois quando utilizada como técnica de coleta de dados é uma grande aliada do entrevistador/pesquisador. Vale ressaltar que isso foi aplicado ao método de valoração contingente, com o uso da disposição a pagar e das duas fases: (1) abordagens open-ended simples; e (2) referendum simples.

\section{As duas fases do estudo}

\section{Fase 1: Abordagem open-ended simples}

A amostragem foi probabilística aleatória (RESENDE, 2013). A determinação do número de formulários empregados nesta fase é muito variada (LOEBLEIN et al., 2018; VASCONCELOS, 2014), então se optou por um número representativo. Nessa abordagem foi utilizado um formulário de caráter misto, para obter informações sobre quais os valores que os frequentadores da Orla Sebastião Miranda estariam dispostos a pagar, anualmente, para as melhorias e conservação do rio Tocantins nesse trecho.

\section{Fase 2: Abordagem referendum simples}

Os indivíduos amostrados nesta fase compõem três grupos sociais: (1) ambulantes, que trabalham na Orla Sebastião Miranda; (2) proprietários ou funcionários de estabelecimentos comerciais e prestadores de serviço, localizados na Av. Marechal Deodoro; e, (3) ribeirinhos da comunidade Carrapato, localizada à margem direita do Tocantins. Todos eles exercem atividades que influenciam diretamente a área da pesquisa, pois estão arrolados na categoria "valores" na composição do VERA, seja pelo valor de uso direto, indireto, opção e existência.

Aqui, foram utilizadas duas equações para análise matemática dos dados disponibilizados pelos 
órgãos públicos (Quadro 1).

Quadro 1: Equações matemáticas utilizadas para o cálculo de população total e amostragem.

\begin{tabular}{|c|c|c|}
\hline Aplicação & Equação & Elementos componentes \\
\hline $\begin{array}{l}\text { Componentes } \\
\text { sociais (populações) }\end{array}$ & $\begin{array}{l}\text { População total }\left(\sum\right)=1+ \\
2+3 \text { (1) }\end{array}$ & $\begin{array}{l}\text { 1- Ambulantes: média dos dados de veraneio e demais períodos, do } \\
\text { Departamento de Postura da Secretaria de Viação e Obras Públicas } \\
\text { (SEVOP); } \\
\text { 2- Estabelecimentos: média entre os dados do Cadastro de Contribuintes } \\
\text { Mobiliários, conforme a Secretaria Municipal de Gestão Fazendária } \\
\text { (SEGFAZ) e, da Secretaria Municipal de Meio Ambiente (SEMMA); } \\
\text { 3- Ribeirinhos: dados cedidos pela Defesa Civil. }\end{array}$ \\
\hline $\begin{array}{l}\text { Amostragem } \\
\text { indivíduos }\end{array}$ & $n=\frac{\sigma^{2} p . q . N}{e^{2}(N-1)+\sigma^{2} p \cdot q}$ & $\begin{array}{l}n=\text { Tamanho da amostra; } \\
\sigma^{2}=\text { Nível de confiança, em número de desvios-padrão; } \\
p=\text { Percentagem em que o fenômeno acontece; } \\
q=\text { Percentagem complementar; } \\
N=\text { Tamanho da população; } \\
e^{2}=\text { Erro máximo. } \\
\text { Nesta pesquisa, foram adotados } \sigma^{2}=1,96 \text { ( } 95 \% \text { de confiança), } \\
p=0,05, q=0,05, e^{2}=0,05, \text { e } \\
N \text { conforme as informações públicas obtidas dos componentes sociais. }\end{array}$ \\
\hline
\end{tabular}

(2) A definição da amostra foi feita de forma individual a cada componente social. Elaborado pelos autores a partir de dados contidos nas literaturas citadas. Fonte: Loeblein et al. (2018).

Após esta seleção aplicou-se o formulário 2, apenas com perguntas objetivas. Ele foi elaborado após a apuração dos dados contidos nos formulários aplicados na fase 1, em que foi utilizado o valor médio de pagamentos para saber se os amostrados pagariam ou não este valor.

\section{Tratamento estatístico dos dados}

Os dados obtidos foram tratados estatisticamente com a utilização de planilhas eletrônicas contidas no software Excel, para a aplicação da Estatística Descritiva, que envolveu os cálculos de frequência absoluta e relativa, e média aritmética (COLVERO et al., 2017). Em seguida, eles foram alocados em tabelas e gráficos, de acordo com a normativa estabelecida pelo Instituto Brasileiro de Geografia e Estatística (IBGE, 1993). Por fim, o cálculo da DAPT foi realizado conforme o preconizado por Carvalho Júnior et al. (2016), com a aplicação da Equação 3 (BENTES et al., 2014).

$$
D A P T=\sum_{i=1}^{n} D A P_{M}\left(\frac{n_{i}}{N}\right)(X)
$$

Onde: $D A P T=$ Disposição a pagar total; $D A P T_{M}=$ Disposição a pagar média; $n_{i}=$ Número de entrevistados dispostos a pagar; $N=$ Número total de entrevistados; $X$ = População total da área durante o período em estudo.

\section{RESULTADOS E DISCUSSÃO}

\section{Abordagem open-ended simples}

Como o número de formulários empregados nessa fase é variado, conforme Loeblein et al. (2018) e Vasconcelos (2014), foi aplicada a quantidade de 40, equivalente a $31 \%$ do total entrevistado na abordagem referendum simples.

\section{Identificação socioeconômica dos indivíduos amostrados}

Os dados obtidos e analisados indicaram que a maioria dos indivíduos amostrados $(n=29 ; 72,5 \%)$ 
não são alvos da pesquisa - transeuntes, devido à aleatoriedade, seguido dos ambulantes $(n=8 ; 20 \%)$, pescadores $(n=2 ; 5 \%)$ e ribeirinhos $(n=1 ; 2,5 \%)$. Indicaram também que houve prevalência mais efetiva do gênero feminino $(n=25 ; 62,5 \%)$ sobre o masculino $(n=15 ; 37,5 \%)$. Todavia, este último, citou os maiores valores quanto à disposição a pagar (Tabela 1).

Tabela 1: Características socioeconômicas dos entrevistados e os valores da disposição a pagar. Marabá-PA.

\begin{tabular}{lllll}
\hline Variável & D.V & $f i$ & $f r(\%)$ & DAPm (R\$) \\
\hline \multirow{2}{*}{ S.E } & Feminino & 25 & 62,5 & 19,20 \\
& Masculino & 15 & 37,5 & 28,66 \\
\hline \multirow{4}{*}{ N.E } & 15 a 30 anos & 18 & 45 & 17,22 \\
& 31 a 45 anos & 16 & 40 & 26,87 \\
& 46 a 60 anos & 3 & 7,5 & 40,00 \\
& acima de 60 anos & 3 & 7,5 & 16,66 \\
\hline & Nunca estudou & 2 & 5 & 5,00 \\
& Fundamental completo & 1 & 2,5 & 100,00 \\
& Fundamental incompleto & 6 & 15 & 22,50 \\
& Médio completo & 14 & 35 & 17,85 \\
M & Médio incompleto & 5 & 12,5 & 50,00 \\
& Superior completo & 5 & 12,5 & 11,00 \\
& Superior incompleto & 7 & 17,5 & 15,71 \\
\hline Total de entrevistados & até $R \$ 500,00$ & 20 & 50 & 32,25 \\
\hline
\end{tabular}

Legendas: D.V - Distribuição da Variável; fi: frequência absoluta; fr - Frequência relativa; DAPm - DAP média; S - Sexo; F.E - Faixas Etárias; N.E - Níveis de Escolaridade; R.M - Renda Mensal per capita.

Já em relação à idade, os dados indicaram que grande parte se encontra entre 15 e 30 anos $(n=18$; 45\%), e os dados obtidos indicaram que as maiores DAP's foram relativas às faixas etárias medianas, de 31 a 60 anos $(n=22 ; 55 \%)$. Quanto ao nível de escolaridade, a análise dos dados indicou que há indivíduos amostrados com o ensino médio completo $(n=14 ; 35 \%)$, e aletrados $(n=2 ; 5 \%)$.

Para os valores obtidos para a DAP (em R\$), os menores valores foram citados pelos indivíduos sem letramento, bem como dos que possuem nível escolar superior, já os valores mais elevados foram citados por aqueles que cursaram o ensino fundamental e médio. Quanto à renda familiar per capita mensal, grande parte dos indivíduos recebe até $R \$ 500,00$ reais $(n=20 ; 50 \%)$, os quais demonstraram maior disposição a pagar pelo rio, mesmo com os menores salários.

No estudo efetuado por Pontes (2014), em Cabo Frio - RJ, no qual foi utilizada a mesma metodologia deste estudo em pesquisa piloto, a maioria dos entrevistados também foram mulheres (60\%), o que corrobora com os dados obtidos nessa pesquisa. Entretanto, sobre a idade, o público mais representativo foi o de 46 a 59 anos (36,9\%). Quanto à escolaridade, grande parte cursou até o ensino médio $(47,69 \%)$, semelhante a esta pesquisa. Em relação à renda, a parcela mais considerável foi de 1 a 3 salários mínimos $(35,4 \%)$, superior ao encontrado em Marabá, e a DAPm foi de $\mathrm{R} \$ 17,94$, próxima ao valor obtido neste estudo.

\section{Percepção ambiental em função do rio Tocantins}

Dessa população, apenas parte dela $(n=17 ; 42,5 \%)$ vai às proximidades do rio com maior frequência (semanalmente), mas a maioria $(n=23 ; 57,5 \%)$ realiza alguma atividade relacionada ao rio Tocantins, 
principalmente o transporte e lazer. Dentre os entrevistados, grande parte deles ( $n=28 ; 70 \%$ ) percebeu a problemática ambiental quanto ao rio, em que quase todos $(n=26 ; 92,8 \%)$ apontam a presença de resíduos e/ou lançamento de esgoto bruto, e os outros $(n=12 ; 30 \%)$ disseram não perceber nenhum problema.

Uma alta percentagem de entrevistados $(95,38 \%)$ também relatou algum problema (Ex.: tarifas elevadas, falta de água e baixa qualidade desta), segundo Pontes (2014), sobre o foco da pesquisa em Cabo Frio, em que $40 \%$ do total amostrado estavam insatisfeitos com os serviços de abastecimento de água, no que tange a qualidade e quantidade do recurso. Em Marabá, é possível que esse percentual tenha sido um pouco inferior porque maioria dos entrevistados $(n=23 ; 57,5 \%)$ visita a Orla com menor frequência, o que dificulta a percepção das problemáticas.

Em relação às notas atribuídas ao estado de conservação do rio, de 1 a 10 , poucas ( $n=23 ; 57,5 \%)$ ficaram entre 1 e 6 , ao considerar o quantitativo que percebeu problemas ambientais, com boa parte entre 7 e $8(n=11 ; 27,5 \%)$, e entre 9 e $10(n=6 ; 15 \%)$. Contudo, em concordância à percepção dos indivíduos aos problemas no rio ( $n=28 ; 70 \%$ ), este mesmo percentual concordou em pagar um valor anual para melhorias na conservação do rio, com uma taxa média de $R \$ 22,75$ reais (Tabela 1), considerando nesta média como zero os quais não estiveram dispostos a contribuir. Ainda que maioria dos entrevistados tenha sido favorável ao pagamento, metade $(n=20 ; 50 \%)$ responsabilizou o governo para a conservação do rio.

Em contrapartida, no estudo de Pontes (2014) a minoria ( $n=22 ; 45,8 \%)$ apresentou DAP positiva, o que pode estar atrelado ao pagamento já existente, cobrado pela concessionária. De qualquer forma, a quantia de DAP's favoráveis ao embolso da taxa nesta fase, na pesquisa em Marabá, mostrou-se promissora para a próxima fase e valoração do rio Tocantins.

\section{Abordagem referendum simples}

Os dados obtidos para a população total (Equação 1) foram de 68 ambulantes, 42 estabelecimentos comerciais/prestadores de serviço e 123 ribeirinhos, um total de 233 indivíduos. Feitos os cálculos da amostragem (Equação 2), o total obtido foi de 190 frequentadores da orla, onde: 58 deles são ambulantes, e atuam na área objeto da pesquisa, 38 são estabelecimentos e, 94 são ribeirinhos. Porém, somente 33 ribeirinhos foram entrevistados, devido à dificuldade de acesso à área, sendo, então, 129 o total de formulários aplicados nesta fase.

Em relação ao valor utilizado nos formulários nesta etapa, relacionado ao pagamento da taxa anual para melhorias na conservação do rio, que foi obtido na pesquisa piloto, realizado também por Oliveira (2015), foi arredondado para $\mathrm{R} \$ 20,00$, e os dados obtidos foram:

\section{Ambulantes}

Os dados obtidos e analisados, para os ambulantes, apontam o predomínio de: gênero feminino ( $n=$ 37; 63,8\%), faixa etária entre 31 e 45 anos ( $n=28 ; 48,3 \%$ ), ensino fundamental incompleto ( $n=18 ; 31 \%)$, renda mensal per capita de até $\mathrm{R} \$ 500,00(n=58 ; 100 \%)$, visita diária às proximidades do rio Tocantins ( $n=$ $32 ; 55,2 \%$ ) e que a maioria deles $(n=56 ; 96,5 \%)$ o utilizam para o desenvolvimento de alguma atividade 
(Tabela 2).

Tabela 2: Dados obtidos para os ambulantes após a análise. Marabá - PA.

\begin{tabular}{|c|c|c|c|}
\hline Variável & D.V & $f i$ & $f r(\%)$ \\
\hline \multirow{2}{*}{$\mathbf{S}$} & Feminino & 37 & 63,8 \\
\hline & Masculino & 21 & 36,2 \\
\hline \multirow{4}{*}{ F.E } & 15 a 30 anos & 17 & 29,3 \\
\hline & 31 a 45 anos & 28 & 48,3 \\
\hline & 46 a 60 anos & 12 & 20,7 \\
\hline & acima de 60 anos & 1 & 1,7 \\
\hline \multirow{5}{*}{ N.E } & Nunca estudou & 6 & 10,3 \\
\hline & Fundamental completo & 13 & 22,4 \\
\hline & Fundamental incompleto & 18 & 31,0 \\
\hline & Médio completo & 11 & 18,1 \\
\hline & Médio incompleto & 10 & 17,2 \\
\hline R.M & até $R \$ 500,00$ & 58 & 100 \\
\hline \multirow{3}{*}{ Res. } & Marabá Pioneira & 54 & 93,1 \\
\hline & Cidade Nova & 1 & 1,7 \\
\hline & Nova Marabá & 3 & 5,1 \\
\hline \multirow{2}{*}{ F.V } & Diária & 32 & 55,2 \\
\hline & Semanal & 26 & 44,8 \\
\hline \multirow{2}{*}{ At. } & Alguma & 56 & 96,5 \\
\hline & Nenhuma & 2 & 3,4 \\
\hline
\end{tabular}

Legendas: D.V - Distribuição da Variável; fi - Frequência absoluta; fr - Frequência relativa; S - Sexo; F.E - Faixas Etárias; N.E - Níveis de Escolaridade; R.M - Renda Mensal per capita; Res. - Reside em qual núcleo de Marabá?; F. V-Frequência da visita à Orla; At. - Exerce alguma atividade em relação do Rio Tocantins.

Em relação aos dados socioeconômicos, dentre os dispostos ao pagamento $(n=45 ; 77,6 \%)$, a maioria corresponde ao gênero feminino $(n=28 ; 48,3 \%)$, faixa etária de 31 a 45 anos $(n=24 ; 41,4 \%)$, com ensino fundamental incompleto $(n=14 ; 24,1 \%)$ e renda de até $\mathrm{R} \$ 500,00(n=45 ; 77,6 \%)$.

Sobre essas variáveis, Silva (2018), realizou pesquisa em sete municípios integrante da Bacia do Rio Acre - AC, acerca da DAP pela preservação e conservação daquele corpo hídrico. Quanto à média dos dados, é representada por indivíduos na faixa etária de 42 anos, nível de escolaridade correspondente ao ensino médio completo e renda de $\mathrm{R} \$ 800,00$, em que maioria $(59,2 \%)$ reside perto ao corpo hídrico. Em Marabá, a faixa etária mais representativa foi de 31 a 45 anos $(n=28 ; 48,3 \%)$, próxima à média obtida no Rio Acre, mas o grau de escolaridade e renda foram majoritariamente inferiores. Isso pode estar relacionado com o tipo de economia desenvolvida em Marabá, e a oferta excessiva de mão-de-obra.

Outros dados obtidos envolveram a percepção ambiental e os problemas existentes no corpo hídrico. Nesta amostra, todos os indivíduos perceberam algum problema ambiental quanto ao rio Tocantins, seja a presença de resíduos ( $n=41 ; 70,7 \%$ ), lançamento de esgoto bruto ( $n=15 ; 25,9 \%$ ) ou odor/coloração acentuados $(n=2 ; 3,4 \%)$. Portanto, as notas atribuídas à conservação do rio foram baixas, de 1 a 4 ( $n=44$; $75,9 \%)$ e de 5 a $6(n=14 ; 24,1 \%)$.

Em relação aos problemas ambientais em rios, Silva (2018) concluiu que, 87\% dos indivíduos participantes da pesquisa identificaram que há lançamento de esgoto bruto naquele rio, o que tornou a água para consumo humano inviável na Bacia do Rio Acre, e isso revelou grau elevado quanto à sensibilidade ambiental $(82,2 \%)$, e informaram que a maioria deles $(90 \%)$, considerou ruim e regular o estado da bacia hidrográfica do rio Acre. 
Em Marabá, a maioria dos indivíduos amostrados ( $n=57 ; 98,3 \%$ ) acreditam que a alteração na disponibilidade, qualitativa e quantitativa, do rio Tocantins, afetaria o próprio bem-estar, então esse mesmo percentual acredita que há um valor para o rio e grande parte deles ( $n=45 ; 77,6 \%)$ estão dispostos a pagar a taxa anual para conservação do corpo hídrico, apenas uma minoria $(n=1 ; 1,7 \%)$ não sabe.

No que tange à disposição a pagar, conforme a pesquisa de Pinto et al. (2017), realizada em João Pessoa - PB, a respeito da percepção e valoração ambiental da Barreira do Cabo Branco, uma área de orla, houve considerável aceitação ( $n=368 ; 83,7 \%$ ) dos entrevistados, um pouco superior ao encontrado em Marabá. Um dos motivos da alta colaboração, em João Pessoa, é atrelado à renda elevada (R\$ 3.123,17 a média individual) daquela população, na qual o gênero feminino foi mais propício ao pagamento. Estes dados corroboram ao observado em Marabá.

Já os que não pagariam ( $n=12 ; 20,7 \%$ ) quanto às melhorias para o rio Tocantins, as razões dividemse entre não possuir condições financeiras e ser responsabilidade da população quanto à sensibilização (ambos com $n=4 ; 6,9 \%$ ), e pagar muitos impostos e ser obrigação do governo (os dois com $n=2 ; 3,4 \%$ ). Em João Pessoa, a principal justificativa foi sobre ser obrigação governamental, e em Marabá foi acerca das condições financeiras, isto condiz com a questão da renda em ambos os estudos.

\section{Estabelecimentos comerciais e prestadores de serviços}

Os dados obtidos e analisados, para os donos e/ou trabalhadores de estabelecimentos, indicam dominância de: gênero masculino ( $n=22 ; 57,9 \%)$, entre 15 e 30 anos ( $n=26 ; 68,4 \%$ ), ensino médio completo ( $n=16 ; 42,1 \%)$, renda familiar per capita de até $\mathrm{R} \$ 500,00(n=25 ; 65,8 \%)$, diariamente estão às proximidades do rio Tocantins ( $n=21 ; 55,3 \%)$ e todos ( $n=38 ; 100 \%)$ utilizam este para o desenvolvimento de alguma atividade (Tabela 3).

Tabela 3: Dados obtidos para os estabelecimentos comerciais ou trabalhadores destes após a análise. Marabá - PA.

\begin{tabular}{|c|c|c|c|}
\hline Variável & D.V & $f i$ & $f r(\%)$ \\
\hline \multirow{2}{*}{$\mathbf{S}$} & Feminino & 16 & 42,1 \\
\hline & Masculino & 22 & 57,9 \\
\hline \multirow{3}{*}{ F.E } & 15 a 30 anos & 26 & 68,4 \\
\hline & 31 a 45 anos & 10 & 26,3 \\
\hline & 46 a 60 anos & 2 & 5,3 \\
\hline \multirow{7}{*}{ N.E } & Nunca estudou & 1 & 2,6 \\
\hline & Fundamental completo & 8 & 21,0 \\
\hline & Fundamental incompleto & 2 & 5,3 \\
\hline & Médio completo & 16 & 42,1 \\
\hline & Médio incompleto & 7 & 18,4 \\
\hline & Superior completo & 1 & 2,6 \\
\hline & Superior incompleto & 3 & 7,9 \\
\hline \multirow{2}{*}{ R.M } & até $R \$ 500,00$ & 25 & 65,8 \\
\hline & $\mathrm{R} \$ 501,00$ a $1.000,00$ & 13 & 34,2 \\
\hline \multirow{3}{*}{ Res. } & Marabá Pioneira & 26 & 68,4 \\
\hline & Cidade Nova & 4 & 10,5 \\
\hline & Nova Marabá & 8 & 21,0 \\
\hline \multirow{2}{*}{ F.V } & Diária & 21 & 55,3 \\
\hline & Semanal & 17 & 44,7 \\
\hline At. & Alguma & 38 & 100 \\
\hline Total de entrevistados & & 38 & 100 \\
\hline
\end{tabular}

Legendas: D.V - Distribuição da Variável; fi - Frequência absoluta; fr - Frequência relativa; S - Sexo; F.E - Faixas Etárias; N.E - Níveis de Escolaridade; R.M - Renda Mensal per capita; Res. - Reside em qual núcleo de Marabá?; F. V-Frequência da visita à Orla; At. - Exerce alguma atividade em relação do Rio Tocantins. 
Dentre os dispostos ao pagamento ( $n=23 ; 60,5 \%)$, sobre os dados socioeconômicos, os mais representativos foram gênero masculino ( $n=14 ; 36,8 \%)$, faixa etária de 15 a 30 anos $(n=17 ; 44,7 \%)$, ensino médio completo ( $n=10 ; 26,3 \%)$ e renda de até $\mathrm{R} \$ 500,00(n=19,50 \%)$, o que está em conformidade ao total entrevistado.

Em estudo de Araújo et al. (2018), realizado em Mossoró - RN, acerca da DAP para a recuperação/preservação do rio Apodi-Mossoró, metade ( $n=150 ; 50 \%)$ da população alcançada foi àquela próxima ao corpo hídrico. Em Marabá isto representa os residentes do núcleo Marabá Pioneira ( $n=26$; $68,4 \%)$, percentual pouco mais elevado que o estudo citado.

Ainda de acordo com aquele autor, Em Mossoró, o predomínio foi de gênero feminino, faixa etária superior aos 50 anos, ensino médio completo e renda média de cerca de $\mathrm{R} \$ 2.600,00$, dados um pouco distantes da pesquisa em Marabá, talvez pela diferença de localidade, ainda que o recurso em Mossoró seja atingido por impactos semelhantes ao Tocantins, como lançamento de resíduos/esgoto e redução de mata ciliar.

No que tange a percepção dos problemas ambientais atrelados ao rio Tocantins, a maioria dos indivíduos amostrados $(n=31 ; 81,6 \%)$ relataram a questão dos resíduos; outros ( $n=6 ; 15,8 \%)$, o lançamento de esgoto sem tratamento; e a minoria $(n=1 ; 2,6 \%)$ não percebeu nada. Logo, as notas dadas ao estado de conservação do rio foram baixas, de 1 a $4(n=23 ; 60,5 \%)$, e de 5 a 6 ( $n=15 ; 39,5 \%)$, em concordância aos fatos apontados.

Acerca da poluição de rio, e a percepção desse problema pela população usuária dele, Sousa et al. (2014), realizaram pesquisa sobre a percepção dos moradores em relação ao rio Buriti, no município de São Bernardo - MA, e os dados que eles obtiveram indicaram que as águas servidas de pia, tanque de lavar roupas e chuveiros, são despejadas nas ruas e adentram ao rio Buriti. Em Marabá, notou-se a percepção dos indivíduos amostrados quanto à ausência de saneamento básico, o que corrobora com a pesquisa efetuada em São Bernardo.

Não obstante, todos amostrados creem que a alteração na disponibilidade do recurso hídrico afetaria o bem-estar destes e acreditam na existência de um valor referente ao rio Tocantins, portanto a maior parte das pessoas ( $n=23 ; 60,5 \%$ ) possuem intenção de pagar a taxa anual para a conservação do ativo, e poucos $(n=2 ; 5,3 \%)$ não sabem.

Sobre esse percentual, que pagaria a taxa anual, este ainda é considerado baixo, já que todos os amostrados acreditam na alteração de bem-estar advinda das mudanças no rio Tocantins e no valor deste. Isto pode ser explicado, conforme destacado por Mombach et al. (2018), em uma pesquisa a respeito da valoração do rio urbano Carahá, e, em Lages - SC, que a carência de senso crítico leva os indivíduos a não apoiar o pagamento, pois já pagam diversos impostos e há, no Brasil, a questão da corrupção e falta de integridade no que tange ao uso do dinheiro público.

Quanto à DAP em Marabá, a parcela não disposta ao pagamento ( $n=13 ; 34,2 \%)$ apresentou motivos distribuídos em ser responsabilidade da população sobre a falta de sensibilização ( $n=6 ; 15,79 \%$ ), pagar muitos impostos ( $n=5 ; 13,2 \%$ ) e não ter condições financeiras ( $n=2 ; 5,3 \%$ ). Sendo que, destes indispostos 
à contribuição, prevalecem ( $n=8 ; 61,5 \%)$ aqueles de maior renda (de $\mathrm{R} \$ 501,00$ a 1.000,00), o que está em consonância ao baixo percentual de respostas referentes a motivos econômicos.

\section{Ribeirinhos}

Os dados obtidos e analisados, para os ribeirinhos, apontam que maior parte é: gênero masculino ( $n$ $=18 ; 54,5 \%)$, entre 46 e 60 anos $(n=13 ; 39,4 \%)$, ensino fundamental incompleto $(n=20 ; 60,6 \%)$, renda familiar per capita de até $\mathrm{R} \$ 500,00(n=22 ; 66,7 \%)$, visita diária nas proximidades do rio Tocantins ( $n=26$; $78,8 \%$ ) e quase todos $(n=31 ; 93,9 \%)$ fazem uso deste para o desenvolvimento de alguma atividade (Tabela 4).

Tabela 4: Dados obtidos para os ribeirinhos após a análise. Marabá - PA.

\begin{tabular}{|c|c|c|c|}
\hline Variável & D.V & fi & $f r(\%)$ \\
\hline \multirow{2}{*}{$\mathbf{S}$} & Feminino & 15 & 45,4 \\
\hline & Masculino & 18 & 54,6 \\
\hline \multirow{4}{*}{ F.E } & 15 a 30 anos & 8 & 24,2 \\
\hline & 31 a 45 anos & 3 & 9,0 \\
\hline & 46 a 60 anos & 13 & 39,4 \\
\hline & acima de 60 anos & 9 & 27,3 \\
\hline \multirow{7}{*}{ N.E } & Nunca estudou & 5 & 15,1 \\
\hline & Fundamental completo & 1 & 3,0 \\
\hline & Fundamental incompleto & 20 & 60,6 \\
\hline & Médio completo & 4 & 12,1 \\
\hline & Médio incompleto & 1 & 3,0 \\
\hline & Superior completo & 1 & 3,0 \\
\hline & Superior incompleto & 1 & 3,0 \\
\hline \multirow{4}{*}{ R.M } & até $\mathrm{R} \$ 500,00$ & 22 & 66,7 \\
\hline & $\mathrm{R} \$ 501,00$ a $1.000,00$ & 8 & 24,2 \\
\hline & $\mathrm{R} \$ 1.001,00$ a $2.000,00$ & 1 & 3,0 \\
\hline & acima de $R \$ 2.000,00$ & 2 & 6,0 \\
\hline Res. & Comunidade Carrapato & 33 & 100 \\
\hline \multirow{2}{*}{ F.V } & Diária & 26 & 78,8 \\
\hline & Semanal & 7 & 21,2 \\
\hline \multirow{2}{*}{ At. } & Alguma & 31 & 93,9 \\
\hline & Nenhuma & 2 & 6,0 \\
\hline \multicolumn{2}{|c|}{ Total de entrevistados } & 33 & 100 \\
\hline
\end{tabular}

Legendas: D.V - Distribuição da Variável; fi - Frequência absoluta; fr - Frequência relativa; S - Sexo; F.E - Faixas Etárias; N.E - Níveis de Escolaridade; R.M - Renda Mensal per capita; Res. - Reside em qual núcleo de Marabá?; F. V-Frequência da visita à Orla; At. - Exerce alguma atividade em relação do Rio Tocantins.

No que diz respeito aos amostrados que manifestaram DAP's positivas ( $n=28 ; 84,8 \%)$, destacaramse o gênero masculino $(n=15 ; 45,5 \%)$, faixa etária de 46 a 60 anos $(n=12 ; 36,7 \%)$, fundamental incompleto ( $n=16 ; 48,5 \%)$ e renda mensal de até $\mathrm{R} \$ 500,00(n=18 ; 54,5 \%)$, semelhantemente aos dados gerais para esta população.

Na pesquisa realizada por Bentes et al. (2014), em Baião, Mocajuba e Cametá, no estado do Pará, sobre uma DAP relacionada a melhorias das condições ambientais do rio Tocantins, em que o dinheiro seria aplicado para um melhor saneamento, retirada de lixo no rio, tratamento da água para consumo e a criação de fossas ecológicas, a aplicação foi feita em ilhas e vilas, e por consequência envolve uma população ribeirinha. Neste estudo, dos quais estiveram dispostos a pagar, a predominância foi: gênero masculino; na faixa etária de 50 a 59 anos, já que puderam contemplar mais os impactos negativos sobre o rio; ensino fundamental; e renda de até $\mathrm{R} \$ 500,00$, mais elevada que a dos indispostos ao pagamento. Isto corrobora 
com os dados encontrados em Marabá.

Em relação à percepção dos problemas ambientais associados ao rio Tocantins, alguns $(n=7 ; 21,2 \%)$ relataram a questão dos resíduos, já outros o lançamento de esgoto sem tratamento e condições ruins à pesca (ambos com $n=2 ; 6,0 \%)$, odor/coloração intensos ( $n=1 ; 3,03 \%)$ e outras questões $(n=7 ; 21,2 \%)$, sendo que quase metade não percebeu nada $(n=14 ; 42,4 \%)$. Consequentemente, as notas dadas ao estado de conservação do rio também foram médias, de 1 a 6 ( $n=16 ; 48,5 \%)$, e de 7 a 10 ( $n=17 ; 51,5 \%)$.

Essa carência quanto à percepção de efeitos negativos no corpo hídrico, e atribuição de notas relativamente elevadas para o estado de conservação deste, podem estar relacionadas à localização da Comunidade Carrapato ser um pouco mais distante da Orla Sebastião Miranda, a qual representa um ponto de maior poluição, conforme Pereira Junior et al. (2017). Logo, por um longo intervalo de tempo é mais difícil visualizar resíduos/odores ou outros poluentes, situação mencionada somente quando atrelada a alguns períodos, em que a variação da quantidade se associa a qualidade do recurso, como em alguns dias durante a vazante do rio.

Assim como uma boa parte não percebeu problemas quanto ao rio Tocantins, nem todos $(n=10$; $30,3 \%$ ) concordam que a alteração na disponibilidade do recurso afetaria o bem-estar destes, os demais ( $n=$ $23 ; 69,7 \%)$ acreditam nisso. Entretanto, apenas poucos não creem na existência de um valor para o rio ( $n=$ $3 ; 9,0 \%)$ ou não sabem $(n=1 ; 3,0 \%)$, então maioria $(n=28 ; 84,8 \%)$ pagaria a taxa anual para a conservação do ativo.

Sobre os indivíduos não favoráveis ao pagamento $(n=5 ; 15,1 \%)$, as causas apontadas são referentes a não ter boas condições financeiras, já pagar muitos impostos e ser responsabilidade do governo (ambos com $n=1 ; 3,0 \%)$, e outros $(n=2 ; 6,0 \%)$. Destes, predominam $(n=4 ; 80 \%)$ aqueles que recebem até $\mathrm{R} \$ 500,00$, o que corrobora com as respostas. Um percentual semelhante $(n=11 ; 1 \%)$, com relação aos indispostos ao pagamento, foi indicado por Delfes et al. (2016), em estudo efetuado para valorar o Rio do Peixe, em Videira $-\mathrm{SC}$.

Na pesquisa realizada por Almeida et al. (2017), em que foi valorado um trecho do rio Cocó, em Fortaleza $-C E$, os entrevistados que rejeitaram o pagamento $(n=63 ; 66 \%)$ apontaram o alto valor de impostos já cobrados, e mesmo assim o rio ser poluído, pensamento que pode ser influenciado pelo fato da maioria da população entrevistada possuir ensino superior incompleto. Isto corrobora com o grande quantitativo de aceitação em pagar observado em Marabá, visto que dessa população maior parte é representada por conter apenas o ensino fundamental incompleto.

\section{Valor da disposição a pagar}

Os dados obtidos e analisados indicam que, nas três populações envolvidas, houve um maior número de respostas positivas à DAP $(n=96 ; 74,4 \%)$, um pouco superior ao encontrado na pesquisa piloto ( $n=28$; 70\%), mas próximo. Quanto ao cálculo da DAPT os dados foram: $\mathrm{DAPm}=20,00$ reais; $\mathrm{ni}=96 ; \mathrm{N}=129$; e $\mathrm{X}=$ 233 indivíduos, para as três populações (respondentes). Isto resultou em uma taxa de R\$ 3.467,907/ano.

Em relação à população do núcleo (Marabá Pioneira) em que foi realizado o estudo, $X=12.020$ 
habitantes, quantitativo que pode estar subestimado, já que se consideraram os dados do Cadastro Municipal do IPTU do ano de 2000, utilizados no trabalho de Pereira Junior et al. (2017), o valor de contribuição equivaleria a $\mathrm{R} \$ 178.902,3 /$ ano.

O núcleo foi considerado pela proximidade de percentual de DAP's favoráveis na pesquisa piloto e final, ou seja, os formulários direcionados e aqueles aplicados aos transeuntes mostraram resultados semelhantes, e boa parte da Marabá Pioneira é transeunte do trecho analisado.

Almeida et al. (2017), acerca da valoração de um trecho do rio Cocó, Fortaleza - CE, os autores encontraram uma DAPT correspondente a $\mathrm{R} \$$ 986.106,5/ano, considerando uma população de 42.578 indivíduos e DAPM de R\$ 23,16/ano. 0 alto valor obtido em Fortaleza é relacionado ao grande quantitativo populacional considerado no cálculo e valor superior de DAPM ao utilizado em Marabá. Se o estudo em Marabá usasse de grandezas semelhantes (população e DAPM), a disposição a pagar total seria de R\$ $733.846,7$, bem mais próximo ao do rio Cocó.

\section{CONCLUSÕES}

Evidencia-se, portanto, alta percepção de problemas ambientais atrelados ao rio, principalmente presença de resíduos e lançamento de esgoto bruto, em que a totalidade dos ambulantes foi perceptiva e a menor atribuição de impactos negativos no recurso foi dada pelos ribeirinhos. Em consonância a isto, o menor quantitativo que acredita na interferência da disponibilidade do recurso no bem-estar próprio foi dos ribeirinhos também, os demais foram altos.

Entretanto, o maior percentual dos favoráveis ao pagamento da taxa anual foi da Comunidade Carrapato, depois os ambulantes, e por último os estabelecimentos comerciais e prestadores de serviços, mas nas três a maioria foi positiva. A minoria, que não pagaria, apontou falta de sensibilização da população, não possuir condições financeiras, já pagar muitos impostos e ser responsabilidade do governo.

Quanto aos valores obtidos na DAPT, foram significativos para a área do estudo, e podem auxiliar em pagamentos de multas e indenizações, haja vista que podem servir de fundamento para compensação ambiental, bem como estes podem propiciar o desenvolvimento de políticas públicas na área, tomada de decisão pública e privada, e direcionamento de outros estudos, já que há carência destes dados na região.

\section{REFERÊNCIAS}

ALMEIDA, B. F. M. A.; MENDONÇA, K. V.; MATOS, F. O. Valoração e percepção ambiental: estudo de caso no baixo curso do rio Cocó, Fortaleza, Ceará, Brasil. Revista IberoAmericana de Ciências Ambientais, v.8, n.2, p.299-306, 2017. DOI: http://doi.org/10.6008/SPC2179$\underline{6858.2017 .002 .0024}$

ARAÚJO, A. B. A.; MAIA, C. E.; ARAÚJO, I. T.. Disposição a pagar pela recuperação/preservação do Rio Apodi-Mossoró. Revista Ibero-Americana de Ciências Ambientais, v.9, n.4, p.297-313, 2018. DOI: http://doi.org/10.6008/CBPC2179$\underline{6858.2018 .004 .0024}$

AREGAY, F. A.; ZHAO, M.; LI, X.; XIA, X.; CHEN, H.. The Local
Residents' Concerns about Environmental Issues in Northwest China. Sustainability, v.8, n.3, 226, 2016. DOI: http://doi.org/10.3390/su8030226

BENTES, E. S.; SANTANA, A. C.; HOMMA, A. K. O.; GOMES, S. C.. Valoração econômica da jusante da barragem de Tucuruí. Revista de Política Agrícola, v.23, n.4, p.102-110, 2014.

CARVALHO, D. W.. Os serviços ecossistêmicos como medidas estruturais para prevenção dos desastres. Revista de Informação Legislativa, v.52, n.206, p.53-65, 2015.

CARVALHO JÚNIOR, L. C.; MARQUES, M. M.; FREIRE, F. S.. Mensuração de ativos culturais: aplicação do método do 
custo de viagem e método de valoração contingente no Memorial Darcy Ribeiro. Revista Brasileira de Pesquisa em Turismo, São Paulo, v.10, n.2, p.394-413, 2016. DOI: http://doi.org/10.7784/rbtur.v10i2.1081

COlVERO, D. A.; CARVALhO, E. H.; PFEIFFER, S. C.; GOMES, A. P.. Avaliação da geração de resíduos sólidos urbanos no estado de Goiás, Brasil: análise estatística de dados.

Engenharia Sanitária e Ambiental, Rio de Janeiro, v.22, n.5, p.931-941, 2017. DOI: http://doi.org/10.1590/s1413$\underline{41522017159448}$

COSTA, M. E. L.; SOUZA, R. T. R. M.; RIBEIRO, A. R.; PASA, M. C.. Respostas de protesto na disposição a pagar espontânea e induzida nas técnicas de lances livres e referendo pelo método de valoração contingente. Biodiversidade, Rondonópolis, v.14, n.1, p.117-144, 2015.

DELFES, M.; PERAZZOLI, M.; GOLDBACH, A.. Valoração ambiental do uso de água na Bacia Hidrográfica do Rio do Peixe no município de Videira, SC. Unoesc e Ciência, Joaçaba, v.7, n.2, p.255-264, 2016.

FAPESPA. Fundação Amazônia de Amparo à Estudos e Pesquisas. Estatísticas Municipais Paraenses: Marabá. Belém: Diretoria de Estatística e de Tecnologia e Gestão da Informação, 2016.

IBGE. Instituto Brasileiro de Geografia e Estatística. Malhas digitais: municipal. Rio de Janeiro: IBGE, 2015.

IBGE. Instituto Brasileiro de Geografia e Estatística. Normas de apresentação tabular. 3 ed. Rio de Janeiro: IBGE, 1993.

JACOSKI, C. A.; HENDGES, C. D.; MATIAZZO, M. F.; BARROS, M. T.. Proposição da valoração ambiental do corte de Araucaria angustifolia (Bert.) Kuntze em área de influência da Estação Ecológica Mata Preta (ESEC), no município de Abelardo Luz (SC). Ambiência, Guarapuava, v.11, n.3, p.651667, 2015. DOI:

http://doi.org/10.5935/ambiencia.2015.03.10

LEANDRO, L. A.; GOMES, C. M.; CASTRO, K. N. V.; CASTRO, E. M. N. V.. O futuro da gestão socioambiental: uma análise crítica sobre a crise ambiental brasileira. Revista de Gestão Ambiental e Sustentabilidade - GeAS, v.4, n.2, p.144-162, 2015.

LIMA, A. L.; MARTINIANO, C. A. A.. As "externalidades" no meio ambiente decorrentes do processo produtivo a luz do princípio da reparação integral. Revista de Direito,

Economia e Desenvolvimento Sustentável, Brasília, v.2, n.1, p.86-102, 2016. DOI:

http://dx.doi.org/10.26668/IndexLawJournals/25260057/2016.v2i1.1669

LIMA, J. L.. A valoração econômica ambiental no Brasil. Diálogos: Economia e Sociedade, Porto Velho, v.2, n.1, p.147-163, 2018.

LOEBLEIN, F.; JESUS-TEIXEIRA, M. D.. Valoração contingente do parque Tia Nair (Brasil): comparação das técnicas OpenEnded e Bidding Games. Economía, Sociedad y Territorio, Toluca, v.18, n.57, p.429-454, 2018. DOI: http://doi.org/10.22136/est20181163

MARABÁ. Lei n. 17.846, de 29 de março de 2018. Dispõe sobre a revisão do Plano Diretor Participativo do município de Marabá, instituído pela lei municipal n. 17.213 de 09 de outubro de 2006, e dá outras providências. Marabá: DOE, 2018.

MATIAS-PEREIRA, J.. Manual de metodologia da pesquisa cientifica. 4 ed. São Paulo: Atlas, 2016.

MOMBACH, G. N. N.; WAHRLICH, J.; CLAUBERG, A. P. C.; BENINCA, L. S.; SIMIONI, F. J.. Valoração ambiental de um rio urbano: uma aplicação do método de valoração contingente em Lages, Santa Catarina. Revista Brasileira de Ciências Ambientais, n.47, p.116-129, 2018. DOI: http://doi.org/10.5327/Z2176-947820180272

MUÑOZ, J. P. M.. Valoração econômica do Parque Nacional de Brasília. Dissertação (Mestrado em Ciências Florestais) Universidade de Brasília, Brasília, 2015.

OLIVEIRA, K. T. L. L.. Análise de valoração contingente das praias do bairro Rio Vermelho, Salvador-BA: uma aplicação dos instrumentos econométricos logit e probit. Nexos Econômicos, v.9, n.1, p.135-162, 2015. DOI: http://dx.doi.org/10.9771/rene.v9i1.21679

PACHECO, S.. A Compensação Financeira pela Utilização dos Recursos Hídricos: pela valorização do tributo socioambiental como fonte de desenvolvimento dos recursos hídricos. Revista de Direito Ambiental e Socioambientalíssimo, Belo Horizonte, v.1, n.2, p.181-207, 2015. DOI:

http://dx.doi.org/10.26668/IndexLawJournals/25259628/2015.v1i1.179

PAIVA, R. F. P. S.. As dimensões de valor dos recursos naturais e os métodos de valoração. Revista lberoAmericana de Economia Ecológica - REVIBEC, v.24, p.203219, 2015.

PEREIRA JUNIOR, A.; OLIVEIRA, G. P.; NICACIO, J. A.; FARIAS, L. J. S.; FARIAS, S. M. S.; COSTA, S. T. L.. Modelo matemático para avaliação da qualidade ambiental: o caso dos núcleos Marabá Pioneira e Nova Marabá, Marabá - PA. Revista Gestão \& Sustentabilidade Ambiental, Florianópolis, v.6, n.3, p.405-423, 2017. DOI: http://dx.doi.org/10.19177/rgsa.v6e32017405-423

PEREIRA JÚNIOR, J. C.. O valor do meio ambiente. Revista Cidadania e Meio Ambiente, v.9, n.49, p.32-33, 2014.

PINTO, A. L. M. S.; FONSECA, M. B.; ARAÚJO, A. F. V.. Percepção ambiental e valoração ambiental: o caso da Barreira do Cabo Branco em João Pessoa - PB. Reflexões Econômicas, llhéus, n.3, v.1, p.57-77, 2017.

PONTES, P. H. A.. Avaliação contingente para a melhoria do abastecimento de água em Cabo Frio-RJ. Dissertação (Mestrado em Ciência) - Universidade Federal de Viçosa, Viçosa, 2014

RADOVIC, V.. Incommensurate Environmental Risks and the Regulator's Dilemma in the Governance of Emergency Situation. Journal of Innovations and Sustainability, v.2, n.4, p.37-52, 2016.

RESENDE, F. M.. Valoração econômica do Parque Nacional da Serra do Cipó (MG): uma aplicação do método 
contingente. Dissertação (Mestrado em Ecologia, Conservação e Manejo da Vida Silvestre) - Universidade Federal de Minas Gerais, Belo Horizonte, 2013.

ROMO-LOZANO, J. L.; LÓPEZ-UPTON, J.; VARGASHERNÁNDEZ, J. J.; ÁVILA-ANGULO, M. L.. Economic valuation of the forest biodiversity in Mexico, a review. Revista Chapingo, Serie Ciencias Forestales y del Ambiente, Chapingo, v.23, n.1, p.75-90, 2017. Dol: http://doi.org/10.5154/r.rchscfa.2016.03.015

SANTOS, L. M.; PORTO, A. J. M.; SAMPAIO, R. S. R.. Direitos de propriedade e instrumentos econômicos de regulação ambiental: uma análise das atribuições implícitas. Revista Brasileira de Políticas Públicas, Brasília, v.7, n.2, p.99-121, 2017. DOI: http://doi.org/10.5102/rbpp.v7i2.4633

SEVERINO, A. J.. Metodologia do trabalho científico. 2 ed. São Paulo: Cortez, 2017.

SILVA, R. G.. Avaliação econômica dos serviços ambientais da Bacia do Rio Acre. Inclusão Social, Brasília, v.12, n.1, p.152160, 2018.

SILVA, V. F.; LIMA, W. R. G.; BEZERRA, C. V. C.; LIMA, V. L. A.; BARACUHY, J. G. V.. Environmental protection through environmental services payments. Ciência e Natura, Santa Maria, v.39, n.3, p.772-776, 2017. DOI:

http://doi.org/10.5902/2179460X28455
SOUSA, E. O. F.; BRITO, N. M.; AMARANTE JÚNIOR, O. P. A.. Percepção ambiental da população urbana próxima ao rio Buriti no município de São Bernardo/MA. Pesquisa em Educação Ambiental, v.9, n.2, p.37-50, 2014. DOI: http://doi.org/10.18675/2177-580X.vol9.n2.p37-50

SOUSA, L. V. C.; ALVES, F. F.. Potenciais contribuições da Nova Economia Institucional para os Pagamentos por Serviços Ambientais. Revista Ibero-Americana de Economia Ecológica - REVIBEC, v.26, n.1, p.45-58, 2016.

SOUSA, T. B.; CUNHA, E. B.. Valoração econômica ambiental: uma estimativa do valor de uso e valor de não uso do rio Amazonas no litoral da capital amapaense. Revista Meio Ambiente e Sustentabilidade, v.3, n.2, p.265-286, 2013.

SOUZA, P. R. P.. Os princípios do Direito Ambiental como instrumentos de efetivação da sustentabilidade do desenvolvimento econômico. Veredas do Direito: direito ambiental e desenvolvimento sustentável, Belo Horizonte, v.13, n.26, p.289-317, 2016. DOI: http://doi.org/10.18623/rvd.v13i26.705

VASCONCELOS, C. S.. Aplicação do método de valoração contingente no Parque Municipal do Itiquira em Formosa GO. Dissertação (Mestrado em Desenvolvimento Sustentável) - Universidade de Brasília, Brasília, 2014.

A CBPC - Companhia Brasileira de Produção Científica (CNPJ: 11.221.422/0001-03) detém os direitos materiais desta publicação. Os direitos referem-se à publicação do trabalho em qualquer parte do mundo, incluindo os direitos às renovações, expansões e disseminações da contribuição, bem como outros direitos subsidiários. Todos os trabalhos publicados eletronicamente poderão posteriormente ser publicados em coletâneas impressas sob coordenação da Sustenere Publishing, da Companhia Brasileira de Produção Científica e seus parceiros autorizados. Os (as) autores (as) preservam os direitos autorais, mas não têm permissão para a publicação da contribuição em outro meio, impresso ou digital, em português ou em tradução. 